\title{
Effect of Height of the Substrate and Width of the Patch on the Performance Characteristics of Microstrip Antenna
}

\author{
R. Mishra, P. Kuchhal, A. Kumar \\ College of Engineering Studies, University of Petroleum \& Energy Studies, Dehradun (India)
}

\begin{tabular}{|c|c|}
\hline Article Info & ABSTRACT \\
\hline Article history: & The demand for broad-band antennas has been increased in the recent years. \\
\hline Received Jul 7, 2015 & $\begin{array}{l}\text { They find to be extensively used in high frequency and high speed data } \\
\text { communication. The factors affecting the bandwidth of the microstrip }\end{array}$ \\
\hline Revised Aug 20, 2015 & antenna is discussed in this paper. There are two main parameters responsible \\
\hline Accepted Sep 4, 2015 & $\begin{array}{l}\text { for the broadening of the antenna. One is the height of the dielectric substrate } \\
\text { and another one is the width of the patch. In this paper, we study the }\end{array}$ \\
\hline Keyword: & $\begin{array}{l}\text { performance characteristics of rectangular patch antenna with variable } \\
\text { thickness of the substrate and width of the patch. One of the parameter is }\end{array}$ \\
\hline Bandwidth & $\begin{array}{l}\text { varied keeping the other fixed and the characteristic effects on resonant } \\
\text { frequency, band width and gain are studied. }\end{array}$ \\
\hline
\end{tabular}

Copyright $(2015$ Institute of Advanced Engineering and Science. All rights reserved.

\section{Corresponding Author:}

R. Mishra,

College of Engineering Studies,

University of Petroleum \& Energy Studies,

PO Bidholi via Premnagar, Dehradun 248007, India

Email: rmishra@ddn.upes.ac.in

\section{INTRODUCTION}

Antenna plays a vital in the communication process. A lot of innovation arises in the designing of the antennas. The microstrip patch antenna is one of the cost effective, easy to integrate and need based one. It also provides the efficient result oriented techniques [1]. A variety of wireless communication engineering system have shown a leap and bound growth in recent years and the extensive need in the coming future. This scenario necessitate the improving of the existing system and a development of new innovations to match with the demand and need [2]. Utility and demand of the ever growing application unleash the antennas as new area of research and innovations. Being economical the printed antennas are accommodated easily in the device package. Microstrip antennas are best form of printed antennas. Their utility and demand lie in their some features that include light in weight, smaller in size, broad in bandwidth, low in cost and integral with integrated circuits, [3], [4] although these antenna have drawbacks like low gain and narrow bandwidth [5] Federal Communication Commission (FCC) recently approved Ultra Wide Band Communication systems operating in the frequency range from 3.1 to $10.6 \mathrm{GHz}$ [6]. This band requires the antennas meet with the requirement of reducing the size and weight of the communication equipment.

Antenna bandwidth is an important parameter of antenna over the range of frequencies fulfilled by the desired antenna characteristics. Antenna bandwidth is described on the basis of gain, Impedance or VSWR. The impedance bandwidth is the range of frequencies over which the input impedance of antenna is perfectly matched to the characteristic impedance of the feeding transmission line. Most common form of antenna bandwidth to be used in microstrip antenna is the fractional bandwidth on a $10 \mathrm{~dB}$ point. To maximize the impedance bandwidth [7] proper impedance matching is required. This requires that the feed at the driving point of the antenna to be of $50 \mathrm{ohm}$ generally. Some researcher [8] introduces half cut printed monopole technique for matching improvement. Wireless communications in its modern form require an 
extensive use of various modification of microstrip antenna [9], [10]. Recently many researcher introduces design aspect [11]-[13], However, in these the focus was to design a specific antenna but not to analyze the impact of patch and substrate dimension detail.

A systematic diagram of the microstrip antenna is given in the Figure 1 below. It is rectangular in shape and has a dimension of $L \times W$. Here $L$ and $W$ are the resonating length and width of the patch. The patch is etched over a substrate of dielectric constant $\varepsilon_{r}$ and height $h$. It is feed with a microstrip line.

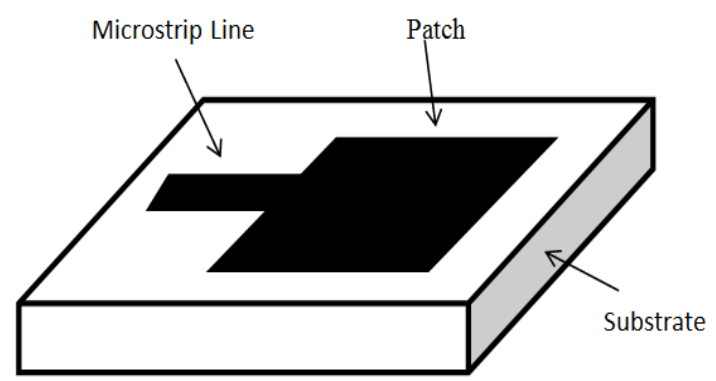

Figure 1. Geometry of Rectangular Microstrip Patch Antenna

Therefore, it is obvious that the microstrip antenna is a non-homogeneous line of two dielectrics, the substrate and the air. Here, most of the electric field lines reside in the substrate. Only some parts of it lie in the air. Therefore in this structure the dominant mode of propagation is quasi-TEM mode. So, the phase velocities are different in the air and the substrate. Hence, an effective dielectric constant $\left(\varepsilon_{e f f}\right)$ comes into the role accounting for the fringing and final the wave propagation in the line. The value of $\varepsilon_{e f f}$ is slightly less than $\varepsilon_{r}$. This is due to the fact that the fringing fields around the boundary surface of the patch are not confined in the dielectric substrate but they also spread in the air.

\section{ANTENNA DIMENSION}

This antenna is fed by a microstrip feed line with a characteristic impedance of $50 \mathrm{ohm}$. The material used for the substrate is FR4 epoxy with dielectric constant of 4.4 and loss tangent of 0.0027 . The material used for the patch is copper and its height is taken to be 18 micrometer.

The patch length determines the resonant frequency, and it is critical parameter in the design. The patch length $L$ of the antenna [14] is given as: $L=\frac{c}{2 f} \times\left(\varepsilon_{r}\right)^{-0.5}$.

Electrically the patch length is bigger than its physical length. Therefore taking into account the normalized extension of the length, the length $\mathrm{L}$ is given as:

$L=\frac{c}{2 f} \times\left(\varepsilon_{r}\right)^{-0.5}-2 \Delta L ; \Delta \mathrm{L}$ arises due to the effective dielectric constant, which is lower than the actual dielectric constant. This effective dielectric constant is used to account for the fringing effect.

The equation used to calculate the width is given as: $W=\frac{c}{2 f} \times\left(\frac{\varepsilon_{r}+1}{2}\right)^{-0.5}$

It is observed that the dimensions are dependent on the permittivity of the substrate. The characteristic impedance of the patch also depends on the dimension and permittivity of the patch antenna.

\section{RESULTS AND ANALYSIS}

The discussion is based on the two set of observation. In the first case of observation the effect on the bandwidth by varying the height of the substrate is seen, while in the second case the height of the substrate is keep fixed, and the width of the patch is varied to observe the variation in the bandwidth.

\subsection{Effect of Bandwidth and Return Loss on the Height of the Substrate}

In this set of observation, the dimension of the antenna is taken as $12 \mathrm{~mm}$ and $16 \mathrm{~mm}$ for a resonant frequency $6 \mathrm{GHz}$ and $10 \mathrm{~mm}$ and $14 \mathrm{~mm}$ with a resonant frequency of $7 \mathrm{GHz}$. The height of the substrate is varied from $1.0 \mathrm{~mm}$ to $2.0 \mathrm{~mm}$. The resonant frequency depends on the no. of modes excited. At around 1.4 $\mathrm{mm}$, the broadening of the bandwidth occurs. As we move towards a higher height of the substrate the more volume to the fringing effects occurred, and this leads to a better return loss and bandwidth. With a height of $1.8 \mathrm{~mm}$ and more the performance degraded. Both the return loss and bandwidth reduces. With more height of the substrate, higher modes are excited and these higher modes result in the degradation of the return loss 
and bandwidth. The two best result is shown in Figure 2 and Figure 3. Figure 2 is with $1.6 \mathrm{~mm}$ of height and resonant frequency of $6 \mathrm{GHz}$, whereas Figure 3 is $1.5 \mathrm{~mm}$ of height and a resonant frequency of $7 \mathrm{GHz}$. since with frequency rise, the dimension of the patch is less, so the better result is obtained at $1.5 \mathrm{~mm}$.

S11

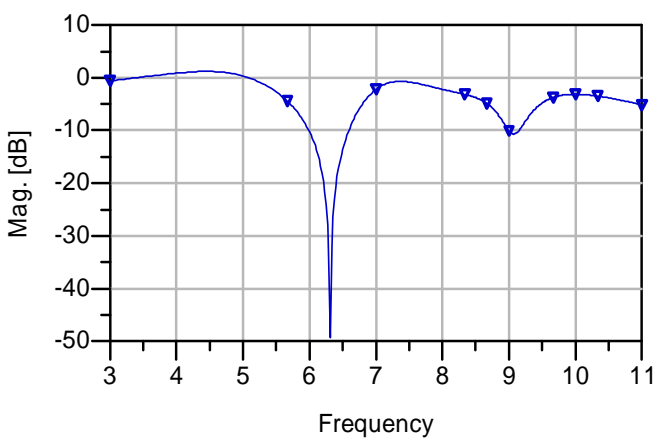

Figure 2. S11 parameter with $1.6 \mathrm{~mm}$ substrate
S11

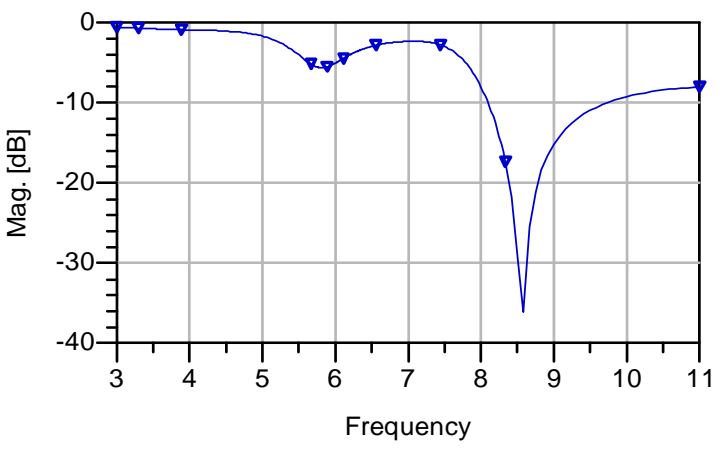

Figure 3. S11 parameter with $1.5 \mathrm{~mm}$ substrate

In order to have a close look into the results observed, the result is plotted in a graphical manner in Figure 4 and 5. The variation of bandwidth is shown in Figure 4, whereas the Figure 5 is the variation of return loss with changing height of substrate. It is obvious from the figure that both these parameter under observation increases steadily with the height of the substrate up to $1.6 \mathrm{~mm}$ for $6 \mathrm{GHz}$ and $1.5 \mathrm{~mm}$ for $7 \mathrm{GHz}$ of frequency, and then started decreasing. So, with FR4 epoxy dielectric substrate material the best height is $1.5 \mathrm{~mm}$ to $1.6 \mathrm{~mm}$ for the designing of the broad patch antenna. However, as the substrate height increases, surface waves are generated. These waves extract power from the total available power in the direction of radiation. Hence a reduction in antenna parameter is observed.

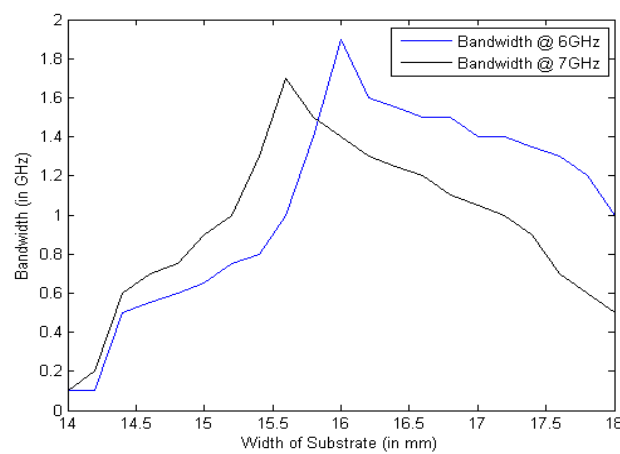

Figure 4. Variation of Bandwidth with Height of Substrate

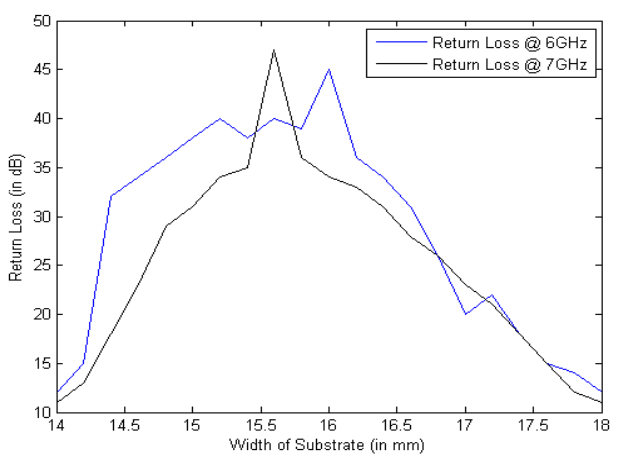

Figure 5. Variation of Return Loss with Height of Substrate

\subsection{Effect on Bandwidth and Return Loss on the Height of the Substrate}

In this observation, the height of the substrate is kept fixed. This is the height at which the best result was obtained in the first set of observation. The length of the patch is kept fixed at $10 \mathrm{~mm}$ and $12 \mathrm{~mm}$ for the two set of frequencies, and the width of the patch is varied from $14 \mathrm{~cm}$ to $18 \mathrm{~cm}$. Different simulation result were observed by varying the width. At lower width there is neither any variation in the broadening nor is a good return loss obtained. As the width increases the bandwidth increased slightly but there is no significant change in the resonant frequency. At a width of around $16 \mathrm{~mm}$ there is a significant change in the bandwidth. The antenna is showing a high bandwidth of more than $1 \mathrm{GHz}$ and a high return loss near to 45 $\mathrm{dB}$. With a width of more than $16 \mathrm{~mm}$, the bandwidth decreased drastically and the resonant frequencies also get changed. The higher mode excitation accounts for it. Figure 6 shows the S11 result with $6 \mathrm{GHz}$ of frequency and Figure 7 is with $7 \mathrm{GHz}$ of frequency at the best observation of return loss and bandwidth. 
S11

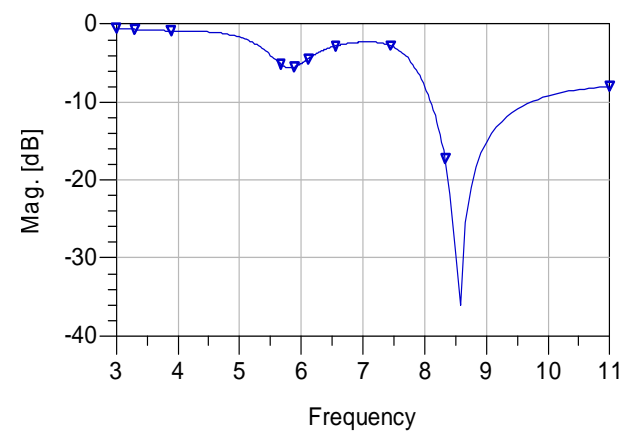

Figure 6. S11 parameter with $14 \mathrm{~mm}$ of width
S11

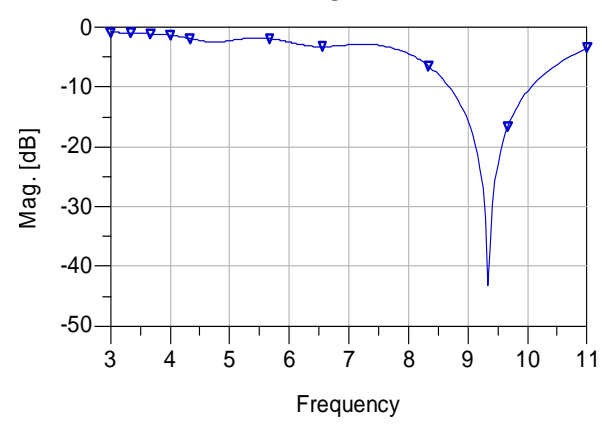

Figure 7. S11 parameter with $15 \mathrm{~mm}$ of width

The variation of these two changing parameter with respect to the changing width of the patch are plotted in Figure 8 and 9. The return is varying in a very steady rate. It is maximum around $16 \mathrm{~mm}$, but below and above this height there it is degrading.

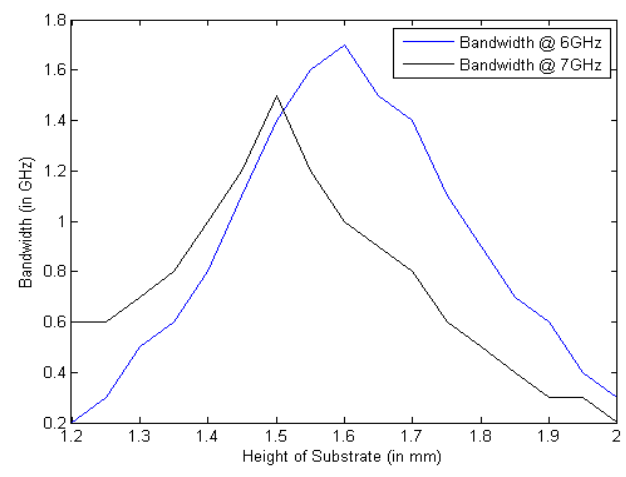

Figure 8. Variation of Bandwidth with Width of Patch

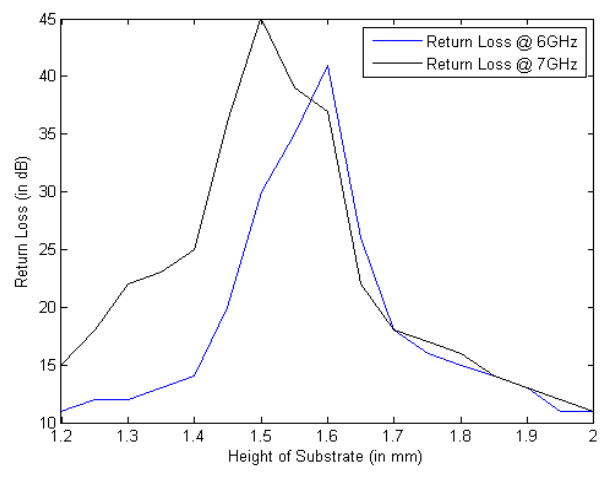

Figure 9. Variation of Bandwidth with Width of Patch

The impedance of the patch is a function of its dimension, therefore it is a general observation that with the changing width, the performance characteristics of the patch changes. A larger patch width increases the power radiated resulting in a reduction in the resonant resistance. It thus increase the operation bandwidth and it finally account for increased radiation efficiency.

As the height of the substrate increases it adds more volume to fringing effect, thereby an increase in the bandwidth and radiation is observed. But beyond a particular value higher modes are exited and the radiation hampers. This results in the reduction in the bandwidth.

\section{CONCLUSION}

The shape of the patch is its main parameter and it naturally affects most of the antenna characteristics. The patch width has a minor effect on the resonant frequency, but it has a major effect on the bandwidth. Similarly, the bandwidth is also effect by the height of the substrate. Therefor height of the substrate and the width of the patch play an important role for the maximizing of the radiation efficiency and the bandwidth of the microstrip antenna. Hence, to get the bandwidth enhancement the width of the patch is around 1.5 time that of the length. By using a proper value a broadband antenna can be designed. 


\section{REFERENCES}

[1] Pozar D. M., "A review of bandwidth enhancement techniques for Microstrip antennas", IEEE Press, New York, 1995.

[2] Niang Z., and X. M. Qing, "Research and development of planar UWB antennas", IEEE APMC-2005 Proceedings, 2005.

[3] R.E. Munson, "Conformal Microstrip phased arrays", IEEE Trans Antennas propagation, Vol. 22, pp. 74-78, 1974.

[4] R. Garg, "Progress in Microstrip antennas", IETE Technical Review, Vol. 18, No.2-3, pp 85-98, 2001.

[5] Federal Communications Commission (FCC), Revision of Part 15 of the Commission's Rules Regarding Ultra Wideband Transmission Systems, First Report and Order, FCC 02-48, 2002.

[6] Kumar G and Ray K.P., “Broadband Microstrip Antennas”, Artech House, 2003.

[7] C. A. Balanis., "Antenna Theory - Analysis and Design”, John Wiley and Sons, NY, 1997.

[8] Teguh Prakoso, "Impedance Mathing Improvement of Half Cut Broadband Printed Monopole Antenna with Microstrip Feeding”, International Journal of Electrical and Computer Engineering (IJECE), Vol. 3, No. 5, pp. 612-617, 2013.

[9] A. Singh, K. Kamakshi, M. Aneesh, J. A. Ansari, "Slots and Notches Loaded Microstrip Patch Antenna for Wireless Communication", TELKOMNIKA Indonesian Journal of Electrical Engineering, Vol. 13, No. 3, pp. 584-594, 2015.

[10] K. K. Parashar, "Design and Analysis of I-Slotted Rectangular Microstrip Patch Antenna for Wireless Application", International Journal of Electrical and Computer Engineering (IJECE), Vol. 4, No. 1, pp. 31-36, 2014.

[11] Dong-Zo Kim, Wang-Ik Son, Won-Gyu Lim, Han-Lim Lee, and Jong-Won Yu, "Integtated planar monopole antenna with microstrip resonators having band-notched characteristics", IEEE Trans. Antennas Propag., Vol. 58, pp. 2837-2842, 2010.

[12] A. M. Abbosh, M. E. Bialkowski, "Design of UWB planar bandnotched antenna using parasitic element", IEEE Trans. Antennas Propag., Vol. 57, pp. 796-799, 2009.

[13] James R. Kelly, Peter S. Hall, and Peter Gardner, "Band-notched UWB antenna incorporating a microstrip openloop resonator", IEEE Trans. Antennas Propag., Vol. 59, pp. 3045-3048, 2011.

[14] R. Garg, P. Bhatia, I. Bahl, and A. Ittipiboon, "Microstrip Antenna Design Handbook”, Artech-House, 2001.

\section{BIOGRAPHIES OF AUTHORS}

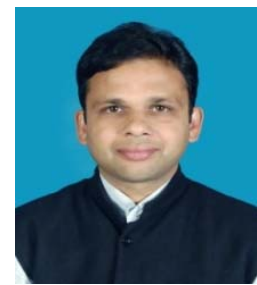

Mr. Ranjan Mishra has done his M. Tech from the University of Burdwan, India. He is presently working as an assistant professor in the department of Electronics, University of Petroleum \& Energy studies, Dehradun India. He is also doing Ph. D. from the same university. His areas of interest are Microstrip antenna, satellite communication.

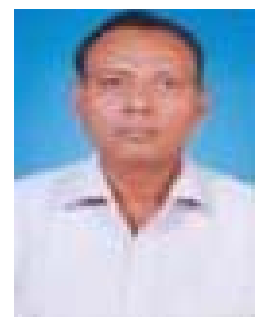

Dr. Piyush Kuchhal is graduate from CCS University Meerut, India, Master in Science and Ph.D from India Institute of Technology, Roorkee (IITR). He is working as the Associate Professor and Associate Dean in College of Engineering Studies, University of Petroleum \& Energy studies, Dehradun India. He also headed the Department of Physics. He is having a rich experience of 20 years in the field of semiconductors devices \& physics and published many papers in international journals. His areas of interest includes Semiconductor material \& process, Electronics devices \& Circuits, Electromagnetic field theory, Optical Communication and Microwave Engineering.

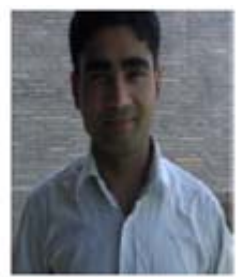

Dr. Adesh Kumar is B.Tech in Electronics \& Communication Engineering from Veera College of Engineering, Bijnor (UPTU, Lucknow) India in 2006. M.Tech in Embedded Systems Technology from SRM University, Chennai in 2008, and Ph.D (Engg) from university of Petroleum and Energy Studies, Dehradun India, 2014. Currently he is working as an Assistant Professor (Senior Grade) with the department of Electronics and Instrumentation Engineering in the University of Petroleum \& Energy Studies, Dehradun India. His are of interest are VLSI Design, Microprocessors and Embedded System. He has published 20 research papers in international journal and conferences. 